\title{
Contratos especiales
}

Iñigo de la Maza Gazmuri

Profesor de Derecho Civil

Universidad Diego Portales

Empresa Minera Oriel Gerardo y Cía. Ltda. con Comercial Minera San Cristóbal Ltda. (Corte Suprema, 9 DE SEPTIEMBRE DE 2014, ROL 17141-2014, CITA EN LÍNEA CL/JUR/6389/2014)

\section{Presentación}

Se trata de los hechos que configuraron el caso que terminó de resolver la Corte Suprema en su sentencia de 9 de septiembre de 2014. Las partes celebraron un contrato de compraventa de unas pertenencias mineras por un precio de $\$ 60.000 .000$, pagándose, en el acto, $\$ 20.000 .000$ y estableciéndose cuatro cuotas mensuales y sucesivas de $\$ 10.000 .000$. Ninguna de esas cuotas fue pagada. La compradora alega que la vendedora no le informó que dichas pertenencias mineras se encontraban hipotecadas a favor de ENAMI, garantizando una deuda de más de $\$ 30.000 .000$.

La vendedora demanda la resolución de la compraventa por no pago. En lo que aquí interesa, la demandada contesta oponiendo una excepción de contrato no cumplido. No controvierte el hecho de no haber pagado lo que adeudaba, sino que señala que la vendedora también ha incumplido. Específicamente, con su obligación de entrega; y más específico aún, dicho incumplimiento habría tenido lugar porque no se le entregó la cosa libre de gravámenes, como lo exigían las cláusulas primera y tercera del contrato de compraventa respectivo.

Las cosas son procesalmente más complicadas; existe una apelación, una casación en la forma y una demanda reconvencional por parte de la demandada. Sin embargo, no hay daño para efectos de este comentario si se prescinde de cómo canalizó sus pretensiones la demandada y, en cambio, se considera cuál era la pretensión referida a las obligaciones de la vendedora, que es lo que interesa aquí.

La pretensión consiste en que el tribunal declare que la vendedora había incumplido con su obligación de entrega y, como ya ha quedado dicho, ese incumplimiento se verificaba porque se entregó una cosa que no estaba libre de gravámenes. La pertenencia minera se encontraba gravada por una hipoteca.

Ni el Tribunal de Andacollo, ni la Corte de Apelaciones de La Serena, ni la Corte Suprema simpatizaron con esta pretensión. La sentencia de la Corte de Apelaciones desarrolla la del Tribunal de Instancia; por su parte, la sentencia de la Corte Suprema frente 
al recurso de casación interpuesto por la compradora señala que dicho recurso procura desvirtuar supuestos fácticos ya asentados -en lo que aquí interesa, el hecho de que la cosa debía entregarse libre de hipotecas y gravámenes.

Resulta, por supuesto, interesante el razonamiento de la Corte Suprema en el sentido de considerar un hecho el que la cosa debía entregarse libre de hipotecas y gravámenes. Y es interesante porque más bien parece ser una cuestión de interpretación contractual. Se trata de fijar el sentido de lo que las partes quisieron decir en el contrato y siendo así, salvo que se estime que las cuestiones relativas a su interpretación no son susceptibles de casación en el fondo ${ }^{1}$.

Como sea que fuere, la Corte $\mathrm{Su}^{-}$ 182 prema dedica una parte importante del considerando $3^{\circ}$ de su sentencia a reproducir los argumentos de la Corte de Apelaciones de La Serena referentes a la obligación de entrega. Convendrá, entonces, en primer lugar, presentar la decisión de la Corte de Apelaciones a este respecto y luego evaluarla.

\section{El Considerando en CUestión}

En su sentencia de 20 de mayo de 2014 (rol No 612-2013) la Corte de Apelaciones de La Serena confirma la sentencia del Tribunal de Letras de Andacollo (rol No 5148-2010). Aquí interesa su opinión respecto a la apelación, específicamente respecto a la

\footnotetext{
${ }^{1}$ Sobre el tema se ha detenido López SANTA MARÍa (2010), pp. 407-413, suministrando buenas razones para estimar lo contrario), procedería el recurso.
}

excepción de contrato no cumplido opuesta por la demandada y justificada en el incumplimiento de la obligación de entrega de la vendedora. Interesa en especial el considerando $4^{\circ}$ de la sentencia de la Corte de Apelaciones. Su tenor es el siguiente:

"Que en cuanto a la primera cuestión señalada y alegada por la apelante, esta la hace consistir en la falta de análisis de la excepción de contrato no cumplido, la cual se basaría en el incumplimiento por parte de la vendedora de entregar la cosa libre de gravámenes, puesto que la cosa vendida en contra de lo que se declara expresamente en el contrato respectivo estaba afecta al gravamen de hipoteca a favor de Enami. Al respecto cabe apuntar que la sentencia apelada señala que no ha resultado probado que existiese un deber $u$ obligación específico de entregar la cosa sin el gravamen de hipoteca, con independencia de las declaraciones que las partes puedan hacer en el contrato, puesto que ellas son únicamente declaraciones y no el establecimiento de una obligación. Y nótese que junto con declarar que la transferencia del bien vendido se hace libre de gravámenes o limitaciones al dominio en la cláusula tercera del contrato, al mismo tiempo en la cláusula cuarta del propio contrato se indica y declara que la entrega material se 
hace en el acto a entera satisfacción del comprador, y con conocimiento del estado jurídico y material del bien vendido, de modo que esta segunda declaración viene a contrarrestar a la primera, y la única forma de armonizarla sería concluir que la primera no excluía la existencia de la hipoteca, la cual en todo caso el comprador -como se declara en el propio contrato de compraventa- conocía, en tanto recibió a su entera satisfacción el bien vendido, y conociendo el estado jurídico del mismo. Pero, aun si no existiese este expreso reconocimiento de recibir el bien a entera satisfacción y con pleno conocimiento de su estado material y jurídico, el comprador pudo y debió tomar conocimiento de la existencia de la hipoteca a favor de Enami con el despliegue de una diligencia mínima destinada a examinar los títulos correspondientes, más aun cuando la hipoteca como consta a fojas 258 está debidamente inscrita y singulariza exactamente las pertenencias mineras que la soportan, como puso de relieve el propio fallo apelado en su Considerando Decimoséptimo.

Por otra parte cabe consignar que es perfectamente posible enajenar un bien hipotecado, y ello no pone al vendedor en un incumplimiento $e x$ ante, y que le impida demandar el cumplimiento forzado o la resolución del contrato frente al no pago del precio por parte del comprador. Otra cosa bien distinta de la que pretende el demandado, es que el vendedor tenga el deber de entregar la cosa, y, en su caso, la obligación de saneamiento por evicción o por vicios redhibitorios, como se dispone en los artículos 1837 y siguientes del Código Civil, pero en el caso que nos ocupa -tal como lo ha indicado la sentencia impugnada- tampoco concurren los presupuestos que permitan sostener que ella se ha configurado en la especie. No hay evicción puesto que el comprador no ha sido privado de la cosa por sentencia judicial. Tampoco hay vicios redhibitorios, ya que la hipoteca de que se trata estaba inscrita regularmente con más de 7 años de antelación a la venta, de modo que tal situación con la debida formalidad por vía de publicidad pudo y debió ser conocida por el comprador si hubiese desplegado un mínimo de diligencia. Es más, si, con todo, fuese efectivo el desconocimiento que alega el comprador demandado, aquel se debería a una negligencia grave de su parte que no resulta excusable desde el punto de vista jurídico, tal como el propio legislador se encarga de establecer en el artículo 1858 regla $3^{\text {a }}$ del Código Civil.

Acierta entonces la sentencia impugnada cuando concluye 
-en el Considerando Decimoctavo- que habiendo entregado la cosa y no concurriendo alguna hipótesis de saneamiento se puede establecer que el vendedor ha cumplido oportunamente su obligación contractual, y no se encuentra en mora".

Convendrá intentar desmontar este largo pasaje en piezas más pequeñas.

- En primer lugar, el tribunal distingue entre declaraciones y obligaciones. No todo aquello que consta en un contrato corresponde a obligaciones, existen textos que deben entenderse como algo distinto: como simples declaraciones que no imponen una obligación. Lo dispuesto en las cláusulas que imponían la entrega sin gravámenes corresponderá a una declaración.

- En segundo lugar, en la cláusula cuarta se indica que la entrega se hace a entera satisfacción del comprador y con conocimiento del estado jurídico y material del bien vendido. De manera que esto contrarresta lo dispuesto por las cláusulas anteriores y la única manera de armonizarlo sería asumir: todos los gravámenes, salvo aquellos conocidos.

- En tercer lugar, aun si no existiera la cláusula cuarta, no se puede alegar desconocimiento de la hipoteca, pues estaba debidamente inscrita, por lo mismo, un despliegue mínimo de diligencia exigía conocerla.
- En cuarto lugar, no incumple quien enajena un bien hipotecado. Cuestión distinta es la protección que suministra la disciplina de la evicción.

- En quinto lugar, no se configuran los requisitos de la evicción.

- En sexto lugar, no existe aquí un vicio redhibitorio, ya que la hipoteca no se encontraba oculta como lo exige el art. 1858.

\section{Cuestiones QUe PUEDEN DESPEJARSE PREVIAMENTE}

Antes de ingresar a las principales cuestiones que deben ser discutidas, convendrá despejar algunas que resultan más sencillas.

Se trata de aquellas que han quedado identificadas en el quinto y sexto lugar. Ante todo, resulta evidente que, en este caso, no se han satisfecho los requisitos que configuran el supuesto de hecho de la tutela que suministra la evicción. La razón es evidente: el acreedor hipotecario no ha intentado una acción en contra de la compradora y, como se sabe desde antiguo, sin esa acción no existe recurso a la tutela que provee el régimen de la evicción (esto, sin perjuicio de la denominada exceptio inminentis evictionis que consagra el art. 1872)2.

Tratándose de los vicios redhibitorios, desde luego hay buenas razones para descartarlos, pero no son las que señala el tribunal. El hecho de que la hipoteca no se encuentre oculta es algo que solo tiene sentido discutir si se

${ }^{2}$ Sobre ella, puede consultarse ALESSANDRI Rodríguez (2003), pp. 295-306. 
considera que, al menos en abstracto, una hipoteca puede contar como un defecto de aquellos que el Código denomina "vicios redhibitorios". Pues bien, en general, se ha estimado que los vicios redhibitorios refieren a defectos materiales -y no jurídicos- de la cosa ${ }^{3}$ $y$, qué duda cabe, una hipoteca no es un defecto físico de la cosa.

\section{Declaraciones y obligaciones}

Qué declaraciones se integran como obligaciones al contrato es una cuestión que ha sido arduamente discutida ${ }^{4}$. Así, por ejemplo, se ha cuestionado si las opiniones que vierten las partes durante la negociación del contrato pueden integrarse obligacionalmente a él. También se ha discutido respecto de las declaraciones públicas de un oferente tratándose de publicidad engañosa y de la integración de la publicidad al contrato ${ }^{5}$.

Respecto de la integración publicitaria existen dos sentencias de la Corte Suprema de fecha 11 de mayo de $2012^{6}$. Ambos fallos se originan en un par de demandas por incumplimiento contractual dirigidas en contra de la Corporación Santo Tomás. Ninguna de las dos pretensiones fue acogida

\footnotetext{
${ }^{3}$ Véase Alessandri Rodríguez (2003), p 213 y más actualmente Oviedo Albán (2010), p. 262.

${ }^{4}$ Véase, por ejemplo, SAIDov (2015), pp. 3141; Barros Bourie y Rojas Covarrubias (2010), pp. 511-526; CARTwright (2007), pp. 21-62; Morales Moreno (2006).

${ }^{5}$ Morales Moreno (2013), pp. 439-454.

${ }^{6}$ Corte Suprema, 11 de mayo de 2012, cita Westlaw: CL/JUR/892/2012 y Corte Suprema, 11 de mayo de 2012, cita Westlaw: CL/ JUR/888/2012
}

por la Corte. Las declaraciones publicitarias que se pretendía integrar al contrato eran las siguientes:

"Por qué estudiar esta carrera. La reforma procesal penal ha creado en Chile, al igual que en otros países latinoamericanos donde se ha implantado la apremiante necesidad de disponer de técnicos y profesionales idóneos que contribuyan al logro de los objetivos de justicia pronta y eficiente que la sociedad reclama".

"La formación que el Instituto Profesional Santo Tomás le otorga al perito forense, está plenamente de acuerdo a los requerimientos definidos en el nuevo proceso penal chileno".

"La carrera de investigación forense es nueva en Chile, y de gran atractivo".

"La puesta en marcha de la Reforma Procesal Penal, que está plenamente vigente al año 2005, augura un gran campo ocupacional y muy interesantes expectativas para los Peritos Forenses".

"Campo ocupacional: El perito forense podrá desempeñarse en: laboratorios de criminalística públicos y privados; como asesor de fiscales del Ministerio Público o de la Defensoría Penal Pública, ejercicio libre de la profesión como perito forense contratado caso a caso, como asesor de oficinas, ejercicio libre de la profesión". 
La Corte Suprema consideró que no se trataba de condiciones objetivas y, por lo tanto, no podían agregarse al contrato. Sin embargo, obiter dicta, agregó lo siguiente:

"Que, a mayor abundamiento, cabe considerar que aún aceptando que la publicidad tantas veces mencionada integra el contrato y forma parte del mismo como una condición objetiva, tal integración no se produciría sino concibiendo al campo educacional en la forma precisa descrita por la demandada, esto es, como una posibilidad futura que puede acontecer o no, naturaleza que impide considerar que aquel asuma la existencia del campo laboral como una obligación".

En otras palabras, aún cuando esas declaraciones se integraran, no podría considerarse que se habían integrado como obligaciones. Comentando un punto similar, Antonio M. Morales Moreno, señala lo siguiente:

“...la oferta publicitaria no siempre va a provocar el nacimiento de deberes de prestación a cargo del contratante que contrata con el consumidor. En ocasiones se refiere a bienes o servicios de un tercero y no determina el nacimiento de ese deber"?.

Ahora bien, el caso que ocupa a este comentario no es uno de integra-

${ }^{7}$ Morales Moreno (2014), p. 249. ción publicitaria; tampoco es uno en el que se discuta si ciertas declaraciones se integraron al contrato o no. Es uno en el cual, indudablemente, la declaración se incorporó. iAparecía en dos cláusulas! La pregunta es si se incorporó de una manera que impedía considerarla como una obligación o no. La respuesta pasa por advertir que lo que las partes hicieron en esas cláusulas fue pactar una entrega sin gravámenes. A continuación, haremos bien en recordar que la entrega es una de las dos obligaciones del vendedor según lo dispone el art. 1824. De esta manera, lo que hicieron las partes, por así decirlo, fue modelar la obligación de entrega ${ }^{8}$, añadiendo que esta solo se entendería cumplida si es que la cosa entregada no se encontraba gravada. Se trata de un pacto perfectamente lícito que, entre nosotros, se acepta, al menos desde la temprana obra de Arturo Alessandri Rodríguez ${ }^{9}$.

Siendo las cosas de esta manera, resulta perfectamente evidente que el argumento de la Corte Suprema es defectuoso, la declaración integró una obligación al contrato de compraventa: la obligación de entregar una cosa sin gravámenes.

\section{Armonizando}

Una cuestión más compleja suscita la convivencia de las cláusulas que modelaban la obligación de entrega en el sentido indicado con aquella cláusula

\footnotetext{
95-114.

${ }^{9}$ Alessandri Rodríguez (2003), tomo I, vol. 2. p. 30.
}

${ }^{8}$ Véase De la Maza Gazmuri (2012), pp. 
según la cual el comprador declaraba recibir la cosa a su entera satisfacción y con conocimiento jurídico y material de su estado. Como se recordará -no obstante considerar que no contenían obligaciones- el tribunal consideró que para armonizar estas cláusulas era necesario entender que la de entrega conforme determinaba que la compradora conocía y aceptaba la hipoteca.

Se trata de una interpretación ingeniosa que, efectivamente, permite convivir a estas tres cláusulas. No es, sin embargo, la única forma de organizar dicha convivencia. Para considerarla puede acudirse a la disciplina de los vicios redhibitorios en los cuales, $m u$ tatis mutandis, se presenta con alguna frecuencia la cuestión de la cláusula de conformidad. La sentencia del Tribunal Supremo español de 22 de febrero de $2007^{10}$ puede contribuir a ilustrar el punto. Se trata de la venta de tres edificios para destinar el terreno a viviendas y estacionamientos. En el contrato se señaló que estaba "libre de cargas", salvo una servidumbre de paso y desagüe. Luego, se añadió que se adquiría

"en el estado de construcción y conservación en que se hallan actualmente, cuya situación declara conocer la entidad compradora".

No obstante, además, existían otros vicios ocultos, entre ellos un refugio antiaéreo proveniente de la guerra civil española carente de signos externos que delataran su existencia. La compradora ejerció la acción de rebaja de precio. El Tribunal Supremo

${ }^{10}$ RJ 2007, 1477. consideró que la declaración según la cual la compradora conocía el estado de los edificios, no obstaba al ejercicio de acciones edilicias, pues:

"Este tipo de cláusulas -que se aproximan más a una cláusula de estilo que a una estipulación expresa- no empecen la aplicación de las normas de saneamiento de cargas y vicios ocultos".

Es probable que, contra la solución del Tribunal Supremo se pueda argumentar que, en el caso que origina esta sentencia, la cláusula que obliga a entregar sin gravamen también deba considerarse como una cláusula de estilo. Y, de aceptar el argumento del Tribunal Supremo, se trata de una poderosa objeción. Siendo así, el escenario quedaría configurado por dos cláusulas de estilo que se contraponen y no existiendo ninguna buena razón para optar por una de ellas en perjuicio de la otra, probablemente, lo más sensato sea no optar por ninguna de ellas y considerar como si ninguna de ellas se encontrara en el contrato.

$\mathrm{Al}$ menos para el examen de esta sentencia el punto no resulta demasiado apremiante. La razón es que el tribunal razona contra fácticamente, considerando qué sucedería si la cláusula $4^{\circ}$ no existiera.

\section{LA CONFIANZA COMO LÍMITE DE LA NEGLIGENCIA}

La Corte de Apelaciones de La Serena estimó que aun si no existiere el 
reconocimiento expreso del conocimiento del estado jurídico de la cosa, la compradora pudo y debió haber tomado conocimiento de la existencia de la hipoteca con el despliegue de una diligencia mínima encaminada a examinar los títulos, por lo demás, con las competentes inscripciones.

$\mathrm{El}$ argumento suena muy persuasivo; después de todo, lo mínimo en la compraventa de un inmueble es examinar los títulos, disponibles -todo habrá que recordarlo- en registros públicos ¿No es, acaso, disminuir los costos de transacción e inyectar certeza al sistema la función de los registros públicos?

$\mathrm{El}$ argumento es persuasivo, pero deja un arista pendiente. La Corte está reflexionando como si la cláusula en que la vendedora afirmaba conocer la situación jurídica de la cosa no existiera. Se trataría, entonces, de un contrato en la que la vendedora declaró que la cosa no tenía gravámenes y se trataría de una situación en la que la declaración de la vendedora era falsa: existe una hipoteca. La verdadera pregunta, entonces, es, ¿qué posición se va a preferir, la de la dueña de la cosa que formuló una declaración falsa o la de la compradora que, confiando en la veracidad de esa declaración no concurrió al registro pertinente a verificar su veracidad?

Refiriéndose al mismo caso, pero en el Derecho español, Cristina López Hernández ha señalado:

“...cuando el vendedor no menciona las cargas que pesan sobre la finca enajenada, y el comprador realmente las des- conoce, aunque estén inscritas, tal comprador tendrá que soportarlas, pero tendrá expedita contra el vendedor la acción rescisoria o la de indemnización de daños y perjuicios"11.

Lo que afirma esta autora es que debe preferirse la posición de la compradora. La razón es sencilla. Fue ella quien emitió una declaración que suscitó la confianza de la vendedora. En este sentido, no es que la compradora no haya desplegado la diligencia mínima, sino que confió razonablemente en la apariencia creada por la vendedora a través de su declaración.

De esta manera, es posible afirmar que la confianza razonable constituye un límite a las conductas que pueden considerarse negligentes.

Para considerar la cuestión de la confianza razonable, la pregunta no es exactamente si la vendedora podía verificar la veracidad de la declaración, sino si existían buenas razones para considerarla falsa. Es decir, si tenía conocimiento acerca de situaciones que la indujeran a pensar que la declaración era falsa. Si carecía de ese conocimiento, todo indica que la disponibilidad de medios para verificar la falsedad de la afirmación no es relevante. Así, por ejemplo, en el Derecho inglés se ha considerado que si una parte confió en lo que la otra declaró, aunque haya tenido medios a su disposición para verificar su veracidad, dicha confianza debe ser protegida ${ }^{12} y$ se ha fallado lo siguiente:

\footnotetext{
${ }^{11}$ López Hernández ( 2008), p. 86.

${ }^{12}$ Cartwright (2007), pp. 66-67.
} 
"The person who has made the misrepresentation cannot be Heard tos ay to the party to whom he has made the representation. You chose to believe me when you might have doubted me, and gone further" ${ }^{\prime \prime}$.

\section{UN INCUMPLIMIENTO} EX ANTE

La Corte de Apelaciones de La Serena señala:

"que es perfectamente posible enajenar un bien hipotecado, y ello no pone al vendedor en un incumplimiento $e x$ ante".

Esto es, correcto, pero también es correcto que es perfectamente posible que la enajenación de un bien hipotecado ponga al vendedor en un incumplimiento ex ante.

¿Cuál ha de ser la línea que separa ambas situaciones? La respuesta es la existencia -o no- de una obligación de entregar sin hipotecas. Como ya ha quedado dicho, se trata de un pacto lícito ${ }^{14}$ que modifica la obligación de entrega, exigiendo para entenderla cumplida no solo el traspaso material y jurídico sino que, además, sin hipotecas. Por lo mismo, el vendedor que entrega un bien hipotecado, incumple con su obligación de entrega. p. 23.

${ }^{13}$ Redgrave v. Hurd [1881] 20 Ch. D. 1, CA,

${ }^{14}$ Véase Alessandri Rodríguez (2003), p. 30
VIII. CONCLusiones

En el problema que se ha examinado aquí, las preguntas más importantes son tres. La primera es si la cláusula que exige una entrega es, nada más una declaración o, en cambio, incorpora una obligación. La respuesta es evidente: incorpora una obligación. La Corte, por lo tanto, yerra en esto.

La segunda pregunta es, ¿̇cómo se organiza la convivencia de esa cláusula con aquella según la cual el comprador declara conocer la situación jurídica de la cosa? Una posibilidad es como lo hace la Corte, señalando que la armonización de las tres cláusulas exige comprender que es sin otros gravámenes distintos de aquellos que conocía la compradora al conocer la situación jurídica de la cosa, por lo tanto, la hipoteca se presumiría conocida por quien compró. Esta solución, que resulta muy atractiva, exige, sin embargo, alguna reflexión sobre qué valor ha de dársele a las cláusulas de estilo.

La tercera pregunta se refiere a la negligencia. La Corte estima que la compradora fue negligente al no consultar el registro pertinente. Empero es posible pensar las cosas de otra manera. No fue negligente, sino que confió en la declaración de la vendedora. La pregunta, en definitiva, es, ċa quién se debe proteger a quien miente o a quien confía en la mentira? La Corte consideró que a quien miente; el principio de la seguridad jurídica parece sugerir una respuesta distinta: a quien confía.

En fin, la cuarta pregunta se refiere a la posibilidad de un incumplimiento ex ante cuando se entrega un bien hipotecado. La respuesta depende de si 
existía o no una obligación de entregar un bien libre de hipotecas.

\section{BiBLIOGRAFÍA CITADA}

Alessandri Rodríguez, Arturo (2003). De la compraventa y de la promesa de venta. Santiago: Editorial Jurídica de Chile. Tomos I y II, vols. 1 y 2.

Barros Bourie, Enrique, y Rojas CoVARRUbias, NicOlÁs (2010). "Responsabilidad por declaraciones y garantías contractuales", en AA.VV., Estudios de Derecho Civil V. Santiago: AbeledoPerrot.

Cartwright, John. (2007). Misrepresentation, Mistake and Non-Disclosure. London, Sweet \& Maxwell.

De la Maza Gazmuri, Iñigo (2012). "Configuración de la obligación de
López Santa María, Jorge (2010). Los contratos. Parte General. $5^{\mathrm{a}}$ ed. actualizada por Fabián Elorriaga de Bonis. Santiago: Thomson Reuters.

Morales Moreno, Antonio Manuel (2006). "Declaraciones públicas y vinculación contractual (Reflexiones sobre una propuesta de Directiva), en El MisMo, La modernización del derecho de obligaciones. Cizur Menor (Navarra): Thomson Civitas.

Morales Moreno Antonio. (2014). La modernización del derecho de obligaciones. Cizur Menor (Navarra): Thomson Civitas.

Oviedo Albán, Jorge (2010). "Sobre el concepto de vicio redhibitorio en la compraventa. Análisis comparado de la jurisprudencia chilena y colombiana". Revista Chilena de Derecho. Vol. 37. No 2. Santiago.

SAIDOv, Djakhongir (2010). Conformity of Goods and Documents. Oxford: Hart Publishing.

\section{Jurisprudencia citada}

Iñigo DE LA MAZA GazMuri, (2013). "La integración publicitaria en el contrato", en AA.VV., Estudios de derecho civil VIIIJornadas Nacionales de Derecho Civil. Pontificia Universidad Católica de Chile. Santiago: Thomson Reuters.

LÓpez Hernández, Cristina Victoria (2008). La protección frente a gravámenes ocultos. Valencia: Tirant lo Blanch.
Corte Suprema, 11 de mayo de 2012, cita Westlaw: CL/JUR/892/2012.

Corte Suprema, 11 de mayo de 2012, cita Westlaw: CL/JUR/888/2012

Redgrave v. Hurd [1881] 20 Ch. D. 1, CA, p. 23.

Sentencia del Tribunal Supremo español de 22 de febrero de 2007. RJ 2007, 1477. 